\title{
PENGARUH METODE DISKUSI BERBANTUKAN MEDIA JOB SHEET TERHADAP HASIL MENJAHIT KEMEJA PRIA SISWA KELAS XI SMK NEGERI 1 KISARAN
}

\author{
Halida Hanim dan Ratna Mahrida Purba ${ }^{*}$ \\ Surel: halidahanimp@gmail.com
}

\begin{abstract}
The study aims to know: 1) The learning outcomes of sewing shirt by using conventional learning method of students grade XI at SMK Negeri 1 Kisaran. 2) The learning outcomes of sewing shirt after using discussion method assisted by job sheet media of students grade XI SMK Negeri 1 Kisaran. 3) How far the influence of learning outcomes of sewing shirt after using discussion method assisted by job sheet media grade XI SMK Negeri 1 Kisaran. This study used a quasi experimental method. The research design used was a post-test control group design. The population in this study were 62 students grade XI fashion at SMK Negeri 1 Kisaran. The samples were two classes randomly selected, each class consisted of 31 students. The first class used a discussion method assisted by job sheet media and the second class used a conventional learning method. The instrument of data collection was the observation sheet. Data were analyzed using t-test analysis technique. Based on the calculations that the level of trends in the learning outcomesof sewing shirt grade XI fashion at SMK Negeri 1 Kisaran for experimental class tend to be high at the 83,9\%. And the tendency level of sewing shirt learning result for the control class tend to be low at $87,1 \%$. The result of hypothesis test by using t-test was 44,04> 1,67 at 5\% significanct level. Therefore, it can be concluded that there is an effect of the application of discussion method assisted by job-sheet media on the learning outcomesof sewing shirt of students grade XI at SMK Negeri 1 Kisaran.
\end{abstract}

Keywords: Discussion Method, Job Sheet Media and Male's Shirt.

\section{PENDAHULUAN}

\footnotetext{
* Dra.Halida Hanim,M.Pd. Dosen Jurusan PKK FT Unimed

*Ratna Mahrida Purba. Mahasiswa Jurusan PKK FT Unimed
} 


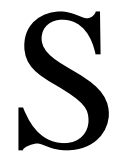

MK Negeri 1 Kisaran merupakan salah satu lembaga pendidikan kejuruan yang memilik program keahlian Pariwisata. Dalam program ini terdapat bidang keahlian tata busana. Salah satu kompetensi yang harus dicapai adalah membuat busana pria Pada proses belajar- mengajar busana pria masih banyak siswa yang mengalami kesulitan dan kurang suka mengikuti proses pembelajaran memperhatikan pelajaran yang berlangsung di ruangan praktek dalam jam pelajaran yang sangat panjang.

Hasil wawancara dengan

Caturini (2015) sebagai ketua jurusandan guru mata pelajaran busanapria bahwa nilai mata pelajaran busana pria, termasuk menjahit kemeja hasilnya kurang optimal belum sesuai dengan nilai Kriteria Ketuntasan Minimum (KKM). Pernyataan ini juga dipertegas dengan hasil terawal yang dilakukan peneliti. Hasil tes menunjukkan bahwa dari 34 siswa, yang mempunyai nilai di atas KKM berjumlah 9 siswa $(26,5 \%)$ dansebanyak $25 \quad \operatorname{siswa}(73,5 \%)$ mempunyi nilai di bawah KKM. Hal ini mungkin disebabkan oleh karena dalam proses pengerjaaan tugas, siswa sering kurang maksimal, tidak tepat waktu dalam mengumpulkan tugas dan hasil jahitan yang tidak maksimai.

Berdasarkan pengamatan peneliti dan wawancara dengan siswa terhadap hasil praktek menjahit kemeja pria dapat diketahui bahwa siswa merasa kesulitan dalm menjahit beberapa bagian kemeja yaitu bagiankerah, plate, manset dan belahannya. Samahalnya dengan hasil ujian tertulis tentang kemeja pria siswa kurang mampu menjelaskan jawaban dari soal- soal yang diberikan, sehingga dapat disimpulkan bahwa siswa kurang memahami penjelasan yang diberikan oleh guru pada saat proses belajar-mengajar. Di samping itu, kegiatan pembelajaran di kelas masih berpusat pada guru. Guru sangat jarang mengajar menggunakan metode dan media yang menarik bagi siswa, sehingga pembelajaran yang disajikan guru kurang diminati siswa, bermuara pada nilai siswa yang kurang optimal. Nilai siswa juga mungkin dipengaruhi oleh rasa jenuh pada saat waktu jam pembelajaran praktek berlangsung panjang, mengakibatkan siswa tidak tertib dan cenderung ribut di kelas. Keadaan kelas seperti ini membuat perhatian siswa pada pelajaran kurang optimal. Kondisi belajar yang tidak tertib seperti ini menuntut guru harus menggunakan metode dan media yang dapat membuat siswa berkerja mandiri dan mendapatkan hasil belajar yang maksimal. Media yang sering digunakan oleh guru saat itu adalah papan tulis dan beberapa fragmen. Karena kemampuan setiap siswa berbeda-beda, maka media tersebut kurang efisien dalam 
membuat kemeja pria yang terdiri dari banyak langkah kerja dalam menjahitnya.

Berdasarkan uraian di atas, diperlukan adanya suatu rancangan proses pembelajaran yang mampu membuat siswa dapat memahami setiap proses menjahit kemeja pria, sehingga dapat meningkatkan hasil menjahit kemeja pria. Metode yang dibantu media yang baik akan mampu membuat proses pembelajaran menjadi sangat menarik minat siswa. Dalam hal ini peran guru sangat penting untuk dapat merancang proses pembelajaran yang menarik dengan menggunakan kombinasi metode dan media yang menarik dan efisien. Kombinasi metode dan media tersebut harus mampu membuat siswa belajar mandiri dan mempermudah guru dalam menyampaikan materi secara utuh dan dipahami oleh siswa dengan baik. Salah satu kombinasi yang baik adalah metode diskusi yang mampu membuat setiap siswa dapat bertanyajawab satu sama lain, sehingga pembelajaran yang disajikan guru lebih menarik dan lebih diminati siswa, dengan demikian siswa tidak merasa jenuh dalam mendiskusikan materi yang harus didiskusikan yaitu materi yang berkaiatan dengan kemeja pria. Metode pembelajaran adalah cara yang digunakan guru untuk menyampaikan pelajaran kepada siswa (Hamdani, 2010). Media adalah komponen sumber belajar atau wahana fisik yang mengandung materi intruksional di lingkungan siswa untuk belajar. Media pembelajaran adalah media yang membawa pesan-pesan atau informasi yang bertujuan intruksional atau mengandung maksud-maksud pengajaran (Hamdani, 2010).

Salah satu media yang mampu untuk mendukung metode diskusi dalam menjahit kemeja pria adalah media job sheet. Media job sheet adalah alat bantu mengajar yang menuntut siswa lebih aktif mencari informasi sendiri baik melalui percobaan, menjawab pertanyaan, maupun membaca buku (Setiawan dalam Kurjono, 2009). Media job sheet diharapkan mampu membuat siswa lebih aktif dalam mengikuti diskusi. Dalam metode diskusi media job sheet sebagai salah satu sumber informasi langkah kerja yang akan dibahas oleh siswa. Hasil penelitian yang dilakukan oleh Sari (2013) menyimpulkan bahwa pembelajaran kompetensi pembuatan kerah kemeja pria pada mata pelajaran keterampilan tata busana dengan menggunakan media job sheet efektifitasnya mencapai 86,7 $\%$. Hasil penelitian Nyiajah (2012) menyimpulkan metode diskusi terbukti sangat efektif meningkatkan hasil belajar. Hasil penelitian Tampubolon (2015) menyimpulkan bahwa ada perbedaan yang signifikan pada nilai hasil belajar 
pembuatan saku pada garis sisi antara pembelajaran yang menggunakan media job sheet dengan pembelajaran konvensional.

Hal inilah yang mendorong penulis untuk mengadakan penelitian yang berjudul pengaruh penerapan metode diskusi berbantukan media job sheet terhadap hasil menjahit kemeja pria.

\section{KAJIAN PUSTAKA DAN HIPOTESIS}

\section{A. Pengertian Metode Diskusi}

Metode merupakan suatu cara yang digunakan untuk mencapai tujuan yang ditetapkan. Dalam kegiatan belajar mengajar, metode diperlukan oleh guru dan penggunaannya bervariasi sesuai tujuan yang ingin dicapai (Syaiful dan Aswan, 2013). Menurut Sumiati dan Asra (2013) metode pembelajaran dapat diartikan sebagai model atau pendekatan pembelajaran, bergantung pada karakteristik pendekatan dan strategi yang akan dipilih.

Dari paparan pendapat mengenai metode pembelajaran diatas dapat disimpulkan bahwa metode pembelajaran adalah beberapa cara yang dapat dilakukan guru untuk menyajikan materi kepada siswa dalam proses belajar mengajar agar tercapai tujuan pembelajaran dengan baik.

Syaiful dan Aswan (2013) menyatakan bahwa metode diskusi adalah cara penyajian pelajaran, dimana siswa-siswa dihadapkan kepada suatu masalah yang bisa berupa pernyataan atau pertanyaan yang bersifat problematis untuk dibahas dan dipecahkan bersama. Di dalam diskusi proses belajar mengajar terjadi, dimana interaksi antara dua atau lebih individu yang terlibat, saling bertukar pengalaman, informasi dan memecahkan masalah.

Sumiati dan Asra (2013) menyatakan bahwa diskusi adalah salah satu metode pembelajaran agar siswa dapat berbagi pengetahuan, pandangan, dan keterampilannya, yang bertujuan untuk mengeksplorasi pendapat atau pandangan yang berbeda dan untuk mengidentifikasi berbagai kemungkinan. Menurut Ibrahim dan Nana (2010) metode diskusi adalah bertukar informasi, pendapat, dan unsur-unsur pengalaman secara teratur dengan maksud untuk dapat pengertian bersama yang lebih jelas dan cermat tentang permasalah atau topik yang sedang dibahas.

Dari pendapat yang diikemukakan diatas dapat disimpulkan bahwa metode diskusi adalah pembelajaran yang dilakukan dengan bertukar fikiran dan pendapat antara siswa dalam suatu proses belajar yang dilakukan untuk memecahkan suatu masalah dan mencapai tujuan pembelajaran.

Dalam diskusi, setiap siswa diharapkan memberikan sumbangan pikiran, sehingga dapat diperoleh pandangan dari berbagai sudut 
tentang masalah yang sedang dibahas. Dengan sumbangan pikiran, siswa akan maju dari satu pemikiran kepemikiran yang lain, langkah demi langkah, sampai dihasilkannya pemikiran yang lengkap mengenai permasalan atau mateti yang dibahas.

\section{B. Media Jobsheet}

Istilah jobsheet berasal dari bahasa inggris yaitu job yang berarti pekerjaan atau kegiatan dan sheet yang artinya helai atau lembaran.Jadi media jobsheet adalah lembar kerja atau lembar kegiatan yang berisi informasi, perintah dan petunjuk pengerjaan. Setiawan dalam Kuncoro (2009) mengemukakan bahwa media pembelajaran jobsheet adalah alat bantu mengajar yang menuntut siswa lebih aktif dalam mencari informasi sendiri baik melakukan percobaan, menjawab pertanyaan maupun membaca buku. Menurut Soryono dalam Widyastuti (2015) jobsheet adalah sebuah buku yang ditulis dengan tujuan agar peserta didik dapat belajar secara mandiri tanpa atau dengan bantuan guru.

Berdasarkan pendapat di atas dapat disimpulkan bahwa media job sheet adalah lembar kerja atau lembar kegiatan yang berisi informasi perintah dan petunjuk mengerjakan suatu tugas, melakukan percobaan, menjawab pertanyaan maupun membaca buku dengan tujuan agar peserta dapat belajar secara mandiri tanpa atau dengan bimbingan guru.

\section{Pengertian Kemeja}

Kemeja berasal dari bahasa Portugis "camisa" adalah sebuah baju atau pakaian atas, terutama untuk pria.Pakaian ini menutupi tangan, bahu, dada, sampai ke perut. Pada umumnya berkerah dan berkancing depan, terbuat dari katun, linen, dan lain sebagainya, ada yang berlengan panjang dan ada yang berlengan pendek. (http://www.artikata.com/arti-

334073-kemeja.html. diakses 22- 072016). Kemeja adalah pakaian luar yang di kenakan pria pada bagian atas badan dan mempunya bukaan pada bagian depan, lengan, krah dengan atau tanpa kaki krah, yang masing-masing mempunyai ukuran tertentu. Bagian badan kemeja harus panjang sehingga dapat dimasukkan kedalam celana. Poewadarmita (2006) menyatakan bahwa kemeja merupakan baju laki-laki yang umumnya berkerah, berkancing baju, yang terbuat dari bahan katun,linen dan lain sebagainya, ada yang berlengan panjang dan ada yang berlengan pendek.

Dari beberapa pendapat diatas dapat disimpulkan bahwa kemeja adalah busana luar pria yang dipakai pada bagian atas, yang menutupi bagian bahu sampai ke pinggang, mempunyai kerah, lengan, kancing dan terbuat dari kain katun, linen dan lain sebagainya, yang dipakai sebagai pasangan celana. Secara garis besar ada 6 bagian 
penting kemeja yang perlu di ketahui diantaranya:kerah, lengan, cuff (manset lengan), placket (kanci depan), yoke (perpotongan bahu), dan pleat (lipit pada tengah belakang).

Adapun hipotesis dalam penelitian ini adalahada pengaruh penggunaan metode diskusi berbantukan media jobsheet terhadap hasil belajar menjahit kemeja pria siswa kelas XI SMK Negeri 1 Kisaran.

\section{METODE PENELITIAN}

\section{A. Desain Penelitian}

Pada penelitian ini desain yang digunakan adalah Posttest Control Group Desain. Sampel yang diambil dalam penelitian ini dibagi atas dua kelas yaitu kelas eksperimen dan kelas kontrol. Untuk kelas eksperimen diberikan metode diskusi berbantukan media jobsheet, sedangkan untuk kelas kontrol tidak menggunakan metode diskusi dan media jobsheet.

\section{B. Tempat dan Waktu Penelitian} Penelitian ini akan dilaksanakan di SMK Negeri 1 Kisaran yang beralamat Jl.Akasia, No. 44, Kisaran Barat, Mekar Baru, Kisaran. Waktu pelaksanaan penelitian semester ganji2016/2017.

\section{Variabel Penelitian}

Variabel $\left(\mathrm{X}_{1}\right)$ : Hasil belajar menjahit kemeja pria dengan menerapkan metode diskusi berbantukan media job sheet. Variabel $\left(\mathrm{X}_{2}\right)$ : Hasil belajar menjahit kemeja pria tanpa menerapkan metode diskusi berbantukan media job sheet.

\section{Populasi dan Sampel Penelitian}

Populasi pada penelitian ini adalah seluruh siswa kelas XI Tata Busana SMK Negeri 1Kisaran sebanyak 62 siswa terdiri dari dua kelas tiap kelas berjumlah 31 siswa. Pengambilan sampel dilakukan dengan total sampling, sehingga jumlah sampel adalah seluruh populasi. .Dalam penentuan kelas kontrol dan eksperimen ditentukan dengan random. Hasil random yang dilakukan pada kedua kelas tersebut adalah kelas XI Tata Busana 1 sebagai kelas eksperimen, dan kelas XI Tata Busana 2 sebagai kelas kontrol.

\section{E. Teknik Pengumpulan Data}

Instrumen yang digunakan untuk menjaring data hasil belajar menjahit kemeja pria yaitu melalui lembar pengamatan kemeja pria, yang telah diuji validitas dan rebialitasnya.

\section{F. Teknik Analisi Data}

Untuk memberikan gambaran terhadap data penelitian maka terlebihdahuludihitung mean (M), standart deviasi (SD) dan uji kecenderungan yang kategorinya disesuaikan dengan kriteria SMK Negeri 1 Kisaran. Untuk menguji 
hipotesis penelitian digunakan teknik analisis uji-t. Sebelumnya dilakukan uji persyaratan analisis yaituu uji normalitas dan homogenitas.

\section{HASIL PENELITIAN}

\section{A. Deskripsi Data Penelitian}

\section{Hasil Belajar Menjahit Kemeja} Priapada Kelas Eksperimen

Nilai ideal tertinggi adalah 100 dan nilai ideal terendah adalah 50. Dari 31 sampel diketahui nilai tertinggi 95 dan nilai terendah 76 dengan rata-rata nilai $(M)=90$ dan standart deviasi $(\mathrm{SD})=4,18$.

Tabel 1. Distribusi Frekuensi Hasil Menjahit Kemeja Pria Kelas Eksperimen

\section{Hasil Belajar Menjahit Kemeja} Pria pada Kelas Kontrol

Berdasarkan data hasil penelitian dengan 31 sampel diketahui nilai tertinggi 84dan nilai terendah 49 dengan rata-rata skor $(\mathrm{M})=68$ dan standart deviasi (SD) $=7,98$.

Tabel 2. Distribusi Frekuensi Hasil Menjahit Kemeja Pria Kelas Kontrol

\begin{tabular}{|c|c|c|c|}
\hline Kelas & $\begin{array}{c}\text { Interval } \\
\text { Nilai }\end{array}$ & $\begin{array}{c}\text { Frek. } \\
\text { Absolut }\end{array}$ & $\begin{array}{c}\text { Frek. } \\
\text { Relatif } \\
(\%)\end{array}$ \\
\hline 1 & $78-84$ & 3 & $9,7 \%$ \\
\hline 2 & $71-77$ & 12 & $38,7 \%$ \\
\hline 3 & $64-70$ & 9 & $29 \%$ \\
\hline 4 & $57-63$ & 4 & $12,9 \%$ \\
\hline 5 & $49-56$ & 3 & $9,7 \%$ \\
\hline \multicolumn{2}{|c|}{ Jumlah } & 31 & $100 \%$ \\
\hline
\end{tabular}

\section{B.Tingkat Kecenderungan Ubahan Penelitian}

1. Hasil Menjahit Kemeja Priapada Kelas Eksperimen

Tabel 3. Tingkat Kecenderungan Hasil Menjahit Kemeja Pria Kelas Eksperimen

\begin{tabular}{|c|c|c|c|}
\hline Keterangan & $\mathbf{f}_{\text {absolut }}$ & $\mathbf{f}_{\text {relatif }}$ & Kategori \\
\hline $95-100$ & 3 & $9,7 \%$ & $\begin{array}{c}\text { Sangat } \\
\text { Tinggi }\end{array}$ \\
\hline $85-94$ & 26 & $\begin{array}{c}83,9 \\
\%\end{array}$ & Tinggi \\
\hline $76-84$ & 2 & $6,4 \%$ & Cukup \\
\hline$<75$ & 0 & $0 \%$ & Kurang \\
\hline Jumlah & 31 & $100 \%$ & \\
\hline
\end{tabular}

Dari tabel 3 di atas dapat dilihat bahwa jumlah responden yang termasuk kategori sangattinggi

\begin{tabular}{|c|c|c|c|}
\hline Kelas & $\begin{array}{c}\text { Interval } \\
\text { Nilai }\end{array}$ & $\begin{array}{c}\text { Frek. } \\
\text { Absolut }\end{array}$ & $\begin{array}{c}\text { Frek. } \\
\text { Relatif } \\
(\%)\end{array}$ \\
\hline 1 & $91-95$ & 15 & $48,4 \%$ \\
\hline 2 & $86-90$ & 12 & $38,7 \%$ \\
\hline 3 & $81-85$ & 3 & $9,7 \%$ \\
\hline 4 & $76-80$ & 1 & $3,2 \%$ \\
\hline \multicolumn{2}{|c|}{ Jumlah } & 31 & $100 \%$ \\
\hline
\end{tabular}
kategori tinggi dengan jumlah 26 siswa (83,9\%), kategori cukup dengan jumlah 2 siswa $(6,4 \%)$ dan kategori kurang tidak ada.Dapat disimpulkan hasil menjahit kemeja priadi kelas eksperimen tergolong dalam kategori tinggi dengan jumlah responden $(83,9 \%)$.

\section{Hasil Menjahit Kemeja Priapada Kelas Kontrol}


Tabel 4. Tingkat Kecenderungan Hasil Menjahit Kemeja PriaKelas

\section{Kontrol}

\begin{tabular}{|c|c|c|c|}
\hline Keterangan & $\mathbf{f}_{\text {absolut }}$ & $\mathbf{f}_{\text {relatif }}$ & Kategori \\
\hline $95-100$ & 0 & $0 \%$ & $\begin{array}{c}\text { Sangat } \\
\text { Tinggi }\end{array}$ \\
\hline $85-94$ & 0 & $0 \%$ & Tinggi \\
\hline $76-84$ & 4 & $\begin{array}{c}12,9 \\
\%\end{array}$ & Cukup \\
\hline kategori & 27 & $\begin{array}{c}87,1 \\
\%\end{array}$ & Kurang \\
\hline Jumlah & 31 & $100 \%$ & \\
\hline \multicolumn{4}{|c|}{ Dari tabel di atas dapat }
\end{tabular}

diketahui bahwa jumlah responden yang termasuk kategori kurang dengan jumlah 27 siswa $(87,1 \%)$, kategori cukup dengan jumlah 4 siswa (12,9\%). Dengan demikian dapat disimpulkan bahwa hasil belajar menjahit kemeja pria di kelas kontrol tergolong dalam kategori kurang.

\section{Pengujian Hipotesis.}

Untuk menguji hipotesis penelitian dilgunakan teknik analisis data uji-t. Sebelum menggunakan uji-t dilakukan perhitungan uji persyaratan analisis, ternyata sebaran data berdistribusi normal dan data mempunyai varians yang sama atau homogen. Berdasarkan hasil perhitungan, diperoleh $t_{\text {kitung }}=44,04$ dan $t_{\text {tabal }}=1,67$ pada taraf signifikan $5 \%$ maka $t_{\text {hitung }}>t_{\text {tabel }}$ =44,04> 1,671. Sesuai dengan kriteria penerimaan dan penolakan hipotesis, maka hipotesis kerja $\left(\mathrm{H}_{\mathrm{a}}\right)$ yang diajukan diterima pada taraf signifikan 5\%, dengan demikian dinyatakan bahwaterdapat pengaruh penerapan metode diskusi berbantukan media jobsheet terhadap hasil menjahit kemeja pada siswa kelas XI SMK Negeri 1 Kisaran.

\section{KESIMPULAN DAN SARAN}

\section{A. Kesimpulan}

1. Hasilmenjahit kemeja pria di kelas eksperimen berada pada tingkat kecendrungan kategori tinggi dengan jumlah $83,9 \%$ responden.

2. Hasil menjahit kemeja priadi kelas controlberada pada tingkat kecendrungan kategori kurangdengan jumlah $87,1 \%$ responden.

3. Berdasarkan hasil pengujian hipotesis diketahui bahwa terdapat pengaruh penerapan metode diskusi berbantukan media jobsheet terhadap hasil menjahit kemeja pria pada siswa kelas XI SMK Negeri 1 Kisaran. Diketahui harga $t_{\text {hitung }}>t_{\text {tabel }}$ atau 44,04>1,67 pada taraf signifikansi $5 \%$

\section{B. Saran}

1. Metode diskusiberbantukan media job sheet mampu meningkatkan mata pelajaran menjahit kemeja pria, untuk itu pihak sekolah dan guru-guru agar menggunakan metode diskusi berbantukan media job sheet sebagai salah satu alternatif metode pembelajaran. 
2. Diharapkan kepada seluruh siswa untuk lebih aktif dalam mengikuti proses pembelajaran yang disajikan guru mata pelajaran busana pria agar hasil belajar dapat terus meningkat.

\section{DAFTAR PUSTAKA}

Arikunto, Suharsimi. (2006). Prosedur Penelitian Suatu Pendekatan Praktik. Jakarta: Bumi Aksara.

Astuti. (2010). Modul Busana Pria. Bandung:Fakultas Teknologi dan Kejuruan UPI.

Daryantodan Sudarto.(2006). TeknikMenjahit PakaianPria. Jakarta: PT. Pembelaan CerdasNusantara.

Djamrah,Syaifulbahri dkk. (2013).Strategi Belajar Mengajar. Jakarta: PT. Rineka Cipta.

Eniwidyasari. (2013).Efektifitas Penggunaan Jobsheet Untuk Pencapaian Kopetensi Pembuatan Kerah Kemeja Pria Pada Keterampilan Tata Busana Di MAN III Yogyakarta. Hasil Penelitian UNY. Yogya:Lembaga Penelitian.

Eka, Wahyu. (2011). Busana Pria. Yogyakarta: PT Intan Sejati Klaten.
Ernawati, dkk. (2008). Tata Busana untuk Jilid2.Jakarta/s/XMNN: Direktorat Pembinaan Sekolah Menengah Kejuruan, Direktorat Jenderal Manajemen Pendidikan Dasar dan Menengah, Departemen Pendidikan Nasional.

Ernawati, dkk. (2008). Tata Busana . Jilid 3.Jakarta/s/XMNN: Direktorat

Hamalik,Oemar. (2006). Proses BelajarMengajar.Jakarta:Bumi Aksara.

SyaifulBahriDjamrahdanZein Aswan. (2013).StrategiBelajarMengaja r. Jakarta: PT. RinekaCipta.

Sudjana Nana danRivai Ahmad. (2010). Media Pengajaran.Bandung: SinarBaruAlgusindo.

SumiatidanAsra. (2009). MetodePembelajaran.Banbung : CV Wacana Prima.

Sukarno. (1992). Pelajaran Menjahit Pakaian Pria Jilid 1. Jakarta: CV Setia Beriman.

Tampubolon, Rika. (2005).PengaruhPenggunaanJ obsheetTerhadapHasil 
BelajarPembuatanSakuSisidi

SMK Negeri 1

Laguboti.Abstrakhasil

penelitian UNIMED. Medan:

Lembagapenelitian.

Wancik. (1997). Bina Busana

Pelajaran Menjahit Pakaian
Pria Buku III. Jakarta: PT

Gramedia Pustaka Utama.

Yogyakarta. Diunduh pada tanggal

22- $07-2015$.

http://www.artikata.com/arti-

334073-kemeja.html. diakses 09-10-2015 